\title{
Long Term Manipulations of Intact Microbial Mat Communities in a Greenhouse Collaboratory: Simulating Earth's Present and Past Field Environments
}

Brad M. Bebout ${ }^{1}$, David J. Des Marais ${ }^{1}$, Mykell Discipulo ${ }^{2}$, Tsegereda Embaye ${ }^{2,}$ Ferran Garcia-Pichel ${ }^{3}$, Mary Hogan ${ }^{4}$, Linda L. Jahnke ${ }^{1}$, Richard M. Keller ${ }^{5}$, Scott R. Miller ${ }^{6}$, Leslie E. Prufert-Bebout ${ }^{1}$, Chris Raleigh ${ }^{7}$, Michael Rothrock ${ }^{3}$, and Kendra Turk ${ }^{4}$

${ }^{1}$ Exobiology Branch, Ames Research Center, NASA; ${ }^{2}$ SETI Institute; ${ }^{3}$ Dept. of Microbiology, Arizona State University; ${ }^{4}$ Institute of Marine Sciences, University of California, Santa Cruz; ${ }^{5}$ Computational Sciences Division, Ames Research Center, NASA; ${ }^{6}$ Department of Genetics, North Carolina State University; ${ }^{7}$ Montana State University

Running Title:

A Microbial Mat Greenhouse Collaboratory

Keywords:

Microbial mat

Biogeochemistry

Biomarkers

Corresponding Author:

Brad Bebout

NASA Ames Research Center

Mail Stop 239-4, Building N239 Room 338

Moffett Field, CA 94035-1000

bbebout@mail.arc.nasa.gov

(650) 604-3227 (office)

(650) 604-1088 (fax)

For submission to: Astrobiology 


\section{Abstract}

Photosynthetic microbial mat communities were obtained from marine hypersaline saltern ponds, maintained in a greenhouse facility, and examined for the effects of salinity variations. Because these microbial mats are considered to be useful analogs of equivalent ancient marine communities, they offer insights about evolutionary events during the $>3$ billion year time interval wherein mats co-evolved with Earth's geosphere and atmosphere. Although photosynthetic mats can be highly dynamic and exhibit extremely high activity, the mats in the present study have been maintained for more than one year with relatively minor changes. The major groups of microorganisms, as assayed using microscopic, genetic, and biomarker methodologies, are essentially the same as those in the original field samples. Field and greenhouse mats were similar with respect to rates of exchange of oxygen and dissolved inorganic carbon across the mat-water interface, both during the day and at night. Field and greenhouse mats exhibited similar rates of efflux of methane and hydrogen. Manipulations of salinity in the water overlying the mats produced changes in the community that strongly resemble those observed in the field. A collaboratory testbed and an array of automated features are being developed to support remote scientific experimentation with the assistance of intelligent software agents. This facility will permit teams of investigators to explore ancient environmental conditions that are rare or absent today but might have influenced the early evolution of these photosynthetic ecosystems. 


\section{Introduction}

Modern microbial mats are thought to be extant representatives of Earth's most ancient ecosystems (Walter, 1976). Geochemical evidence of the existence of photosynthetic microbial mats, and their mineralized counterparts, stromatolites, has been identified in

rocks as old as $3.0 \mathrm{Ga}$ (Beukes and Lowe, 1989). As a living repository of genetic, physiological, isotopic, and biogeochemical information on the co-evolution of a planet and the only biosphere known, modern microbial mats are invaluable objects of study. Modern microbial mat studies have provided important insights on rates of biological activity (Revsbech et al., 1983; Canfield and Des Marais, 1993; Des Marais, 1995), genetic diversity (Ward et al., 1990; Garcia-Pichel et al., 1998; Nübel et al., 2001), stable isotopic fractionation (Schidlowski, 1988; Des Marais and Canfield, 1994), organic (Boon, 1984; Ward et al., 1985), and atmospheric (Visscher and Van Gemerden, 1991; Visscher and Kiene, 1994; Hoehler et al., 2001) biomarkers, as well as minerals, (Reid et al., 2000) that have been used to interpret the fossil record of these communities over geologic time.

Photosynthetic microbial mats are self-sustaining, complete ecosystems in which light energy absorbed over a diel (24 hour) cycle drives the synthesis of spatially-organized, diverse biomass. Microorganisms with tightly-coupled metabolism in the mat catalyze transformations of carbon, nitrogen, sulfur, and metals. Radiant energy form the sun sustains oxygenic and anoxygenic photosynthesis, which in turn provides chemical energy, as organic photosynthates and oxygen, to the rest of the community. When oxygenic photosynthesis ceases at night, the upper layers of the mat become highly reduced and sulfidic (Jorgensen et al., 1979). Counteracting gradients of oxygen and sulfide shape the chemical environment and provide daily-contrasting microenvironments separated on a scale of a few millimeters (Revsbech et al., 1983; Revsbech and Jørgensen, 1986). While photosynthetic bacteria dominate the biomass and productivity of the mat, many aspects of the ecosystem's emergent behavior may ultimately depend on the associated non-photosynthetic microbial communities, including the anaerobes. Additionally, transformation of photosynthetic productivity by the microbial community may contribute diagnostic "biosignature" gases that could represent search targets for remote spectroscopic life detection efforts (e.g., Terrestrial Planet Finder, (Des Marais et al., 2001)). To understand the overall structure and function of mat communities, it is thus critical to determine the nature and extent of the interactions between phototrophic and nonphotosynthetic microorganisms, including anaerobic microorganisms.

Compared to their historical distribution and abundance, microbial mats are today confined to a relatively restricted number of habitats. Well-developed modern photosynthetic mats occur both in high salinity, and high temperature environments. This 
restricted distribution is thought to be due primarily to the higher rates of grazing in more moderate modern environments (Garret, 1970), although alternative hypotheses have been forwarded. In any event, the limited geographical distribution of mats on the present day Earth also serves to limit their usefulness as analogues of similar ecosystems growing in more diverse ancient environments. Environments that are not well represented on the modern Earth, but which have been extremely important over evolutionary time, include marine environments having low concentrations of sulfate, and/or free oxygen (Holland, 1984; Canfield and Teske, 1996).

The effects of various environmental parameters important in Earth's past (such as sulfate and oxygen concentrations) on microbial processes may be studied in culture. However, the emergent properties of complex microbial ecosystems are not necessarily predictable, nor understandable, on the basis of these types of experiments (Wilson and Botkin, 1990). Some microbial processes either do not occur in culture (e.g., anaerobic methane oxidation, (Reeburgh, 1980), and sulfate reduction under aerobic conditions (Canfield and Des Marais, 1991)) or occur at rates vastly different than rates observed in nature. In addition, relatively few (less than $1 \%$ ) of the total number of microbes present in nature are available in culture (Ward et al., 1990; Amann et al., 1995). A microbial mat is a highly complex assemblage of organisms possessing many different modes of metabolism, all of which are interacting with each other at some level in beneficial and/or competitive ways. The end products of the metabolism of one group of organisms frequently constitute the substrates of another. These considerations argue for an alternative approach in which the entire microbial ecosystem is subjected to the experimental manipulation.

To attain several key objectives in astrobiology, we must understand better the mechanisms and rates at which trace gases are produced and consumed by microbial ecosystems. As dominant components of our biosphere for at least 2 billion years of its more than 3.5 billion year history, microbial mats played a pivotal role in shaping the composition of Earth's early atmosphere, including its eventual oxygenation. NASA's present search strategy for the detection of life on extrasolar planets includes the observation and interpretation of spectral features of biogenic gases in remote atmospheres (Caroff and Des Marais, 2000; Des Marais et al., 2001). However, the current strategy relies principally upon the detection of $\mathrm{O}_{2}$, and thus might preclude the detection of life that might resemble our own pre-oxygenated biosphere for as much as 2 billion years of its early existence. Clearly, the rates of production and consumption of reduced gases by microbial communities over geologic time must be better constrained in order to enhance our search for life elsewhere. The use of simulation facilities, such as the greenhouse described here, will augment that endeavor. 
We report here on our attempts to maintain intact modern photosynthetic microbial mats under approximate in situ conditions, and to monitor the responses of these mats to experimental manipulations. We have constructed a facility in which photosynthetic microbial mats can be maintained over long periods of time, using natural illumination and realistic water flow and other environmental conditions. We describe here the results of our first experiment, in which we used this facility to manipulate the salinity of water overlying the mats. As variations in salinity also occur in the natural environment where these mats were collected, we are able to assess on the degree to which our experimental facility can reproduce naturally occurring phenomena. Future uses of this experimental system, in which conditions not presently found in the modern environment will be simulated, are discussed.

\section{Materials and Methods}

Field Site

Microbial mats were collected in salterns managed by the salt producing company Exportadora de Sal. S.A. de C.V., located on the Pacific Ocean side of the Baja peninsula, Baja California Sur, Mexico. This field site has been previously described in detail (Des Marais, 1995). Briefly, lagoon water, having a salinity of ca. 40 parts per thousand (\%) is pumped through a series of concentrating ponds, or Areas, and then crystallizing, ponds, or Vasos. The salinity of the water is gradually raised until it becomes saturated with respect to sodium chloride, at which point the brine is pumped out of the crystallizing pond, and the salt is harvested. Extensive and well-developed microbial mat growth occurs in concentrating areas in which the salinity is between approximately $65 \%$ and $130 \%$.

Microbial mats were collected on May 27, 2000 from two localities: Area 4, near the dike separating Area 4 from Area $5\left(27^{\circ} 41.3450^{\prime} \mathrm{N}, 113^{\circ} 55.0270^{\prime} \mathrm{W}\right)$ and Area 5, near the dike separating Area 5 from Area $6\left(27^{\circ} 44.4140^{\prime} \mathrm{N}, 113^{\circ} 54.7950^{\prime} \mathrm{W}\right)$. At the time of the collection, the salinities of the Area 4 and Area 5 were ca. $90 \%$, and ca. $120 \%$ respectively. Microbial mats in both of these locations are ca. $5 \mathrm{~cm}$ thick and are well laminated. The dominant cyanobacterium of the mat community is Microcoleus chthonoplastes. Sections of mat ca. $20 \mathrm{~cm} \times 25 \mathrm{~cm}$ were cut and removed from the bottom of the concentrating pond by divers using metal spatulas and were immediately placed into tight fitting black acrylic trays. In this way, exposure of the deeper anaerobic layers of the mats to air was minimized. Mats were covered with relatively high salinity water $(180 \%$ ) overnight in an effort to slow overall metabolic rates for transport. The trays containing the mats were then transported by vans back to our laboratory in larger plastic trays covered by tight fitting plastic film. In this way, the mats were kept moist but not covered with water, and were exposed to some natural light over the ca. 48 hours 
required for the relocation. Although 6 mats from Area 5 and 12 mats from Area 4 were maintained in the greenhouse throughout the entire experiment, results from only the Area 4 mats will be presented here.

\section{Greenhouse Facility}

Upon arrival at Ames Research Center, the mats were transferred to a greenhouse modified for these experiments by replacing the original glass with ultraviolet transparent OP-4 acrylic (transmission in the UV-B, UV-A, and visible ca. 90\% in the greenhouse). Mats were placed onto a specially built table (Figure 1) having six clear acrylic flow boxes, each flow box holding three trays of mat. Brine used for the experiment was collected from one of the higher salinity concentrating areas that had retained its original complement of seawater solutes, and diluted with deionized water to the appropriate salinity. Mats were arbitrarily assigned to one of two salinity treatments on the table. Three of the flow boxes recirculated brine collected from the field site, and diluted to the in situ salinity of $90 \%$ (hereafter referred to as the NORMAL salinity treatment), the other three flow boxes recirculated brine having an elevated salinity of $120 \%$ (hereafter referred to as the HIGH salinity treatment). Water was recirculated from a single reservoir holding 60 liters of brine through the three interconnected flow boxes which constituted each of the two salinity treatments. The flowboxes assigned to each of the salinity treatments were interspersed on the table, so that the treatments alternated, e.g., NORMAL, HIGH, NORMAL, etc. Salinity was maintained at these levels over the course of the experiment with additions of deionized water to replace losses due to evaporation. Temperature control of the air in the greenhouse was achieved with a combination of an evaporative cooler and propane heater. Precise temperature control of the water being recirculated over the mats was achieved by circulating temperaturecontrolled water through titanium heat exchanging coils submerged in the reservoirs. Normal in situ daily water column temperature variations were simulated in the greenhouse.

\section{Environmental Data}

Water column salinity was determined using a refractometer (Delta model, Bellingham + Stanley, Tunbridge Wells, UK), corrected for temperature effects at each reading. Temperature was recorded at 10 minute intervals throughout the experiment using data loggers (StowAway TidbiT, Onset Computer Corporation Bourne, Massachusetts, USA). Light was monitored, and averaged at 10 minute intervals, using a data logger coupled to a terrestrial quantum sensor (LI-1000 and LI-192SA, LI-COR, Inc., Lincoln, Nebraska, USA). 


\section{Greenhouse Oxygen Microelectrode Measurements}

Oxygen concentrations within the microbial mats were monitored at various times throughout the course of the experiment using oxygen microelectrodes. We used Clarktype microelectrodes incorporating guard cathodes (Diamond General 737-GC, Diamond General Development Corporation, Ann Arbor, Michigan, USA). In the initial phase of the experiment, microelectrodes were positioned using motorized micromaniupulators mounted to bases placed across the flow boxes. Halfway through the experiment, the microsensors were transitioned to a positioning system using a robotic $\mathrm{XYZ}$ positioning system installed over the flow boxes. In all cases, the positioning was controlled by, and data acquired with, custom software written in the LabVIEW programming environment (National Instruments Corporation, Austin, Texas, USA). Oxygen microelectrode signal output was calibrated to oxygen concentrations using a two point calibration; the output of the electrode at oxygen concentrations of zero was provided by the asymptotic minimum of electrode current within the lower parts of the mat, the electrode current in the overlying water was taken to represent the air-saturated oxygen concentration at that temperature and salinity, using published values. In general, the electrodes were advanced within the mat at 100 micrometer steps.

\section{In situ Microelectrode Measurements}

Measurements of in situ concentrations of oxygen within the microbial mat were made using a diver operated microprofiler (Unisense, Århus, Denmark) at 100 micrometer intervals. Calibrations of the oxygen electrode were performed as described for greenhouse microelectrodes (above).

\section{Community Composition Analyses}

\section{Light Microscopy}

Microbial community composition was followed throughout the course of the experiment using a variety of techniques. First order observations about the community were made using light microscopy (Nikon Microphot FX/A, Nikon USA)

\section{Cyanobacterial $16 S$ rRNA gene fingerprints by $P C R / D G G E$}

Cores ( $10 \mathrm{~mm}$ in diameter) were taken from the microbial mats on $9 / 15 / 00$, and the photic zone (top $3 \mathrm{~mm}$ ) was aseptically removed. The samples were homogenized in a Tenbroeck tissue grinder (VWR Scientific Products, Brisbane, California, USA). Cell lysis and DNA extraction was performed as previously described (Nübel et al., 1997). In short, the homogenized samples were frozen and thawed repeatedly, followed by incubation with $1 \%$ sodium dodecyl sulfate and proteinase $\mathrm{K}$. DNA extraction was performed using hexadecylmethylammonium bromide $(\mathrm{CTAB})$ in conjunction with phenol:chloroform:isoamyl alcohol (25:24:1), followed by isopropyl alcohol precipitation. Cyanobacterial/plastid specific PCR amplification was carried out using the 
oligonucleotide primers CYA359F (with a 40-nucleotide GC-rich sequence at the 5' end) and CYA805R were used for specific amplification of 16S rRNA genes from cyanobacteria and plastids (Nübel et al., 1997). Each 50- $\mu \mathrm{L}$ PCR reaction (5 $\mu \mathrm{L}$ of $10 \mathrm{X}$ Takara Ex Taq ${ }^{\text {TM }}$ PCR buffer (PanVera Corporation, Madison, Wisconsin, USA), $4 \mu \mathrm{L}$ of Takara dNTP mixture (2.5 mM each), 50 pmol of each primer, $200 \mu \mathrm{g}$ of BSA, $10 \mu \mathrm{L}$ of $5 \mathrm{X}$ Eppendorf TaqMaster ${ }^{\mathrm{TM}}$ PCR-enhancer (Brinkmann Instruments, Inc., Westbury, New York, USA), and 15 ng of DNA extract. Thermocycling) was performed using a Bio-Rad iCycler ${ }^{\text {TM }}$ thermal cycler (Bio-Rad Laboratories, Hercules, California, USA). After an initial denaturation at $94{ }^{\circ} \mathrm{C}$ for 5 min (hot start), 2.5 units of Takara Ex Taq ${ }^{\text {TM }}$ DNA polymerase was added to the reaction at $80^{\circ} \mathrm{C}$. 35 cycles of $1 \mathrm{~min}$ each at $94^{\circ} \mathrm{C}$ (denaturation), $60^{\circ} \mathrm{C}$ (annealing), and $72{ }^{\circ} \mathrm{C}$ (extension) were performed and the reaction finished with a final extension at $72^{\circ} \mathrm{C}$ for $9 \mathrm{~min}$. Gels were imaged using a Bio-Rad Fluor- $\mathrm{S}^{\mathrm{TM}}$ MultiImager system. For DGGE band sequencing, each band was excised using a sterile scalpel and DNA allowed to diffuse out for $3 \mathrm{~d}$ at $4{ }^{\circ} \mathrm{C}$ in $50 \mu \mathrm{L}$ of 10 $\mathrm{mM}$ Tris buffer. $1 \mu \mathrm{L}$ of the solution was PCR amplified using the same primers, reaction mixture and thermocycling conditions. A kit was used to purify PCR product (Qiagen, Inc., Valencia, California, USA) and $150 \mathrm{ng}$ was commercially sequenced in two separate reactions (5' to 3' and 3' to 5'). Complementary sequences were matched, aligned, and edited using Sequence Navigator (Applied Biosystems, Foster City, California, USA) and submitted to the BLAST search engine (National Center for Biotechnology Information, www.ncbi.nlm.nih.gov) for phylogenetic matching.

\section{Lipid Biomarker Analysis}

Gas chromatographic profiles of fatty acids (FA) (as fatty acid methyl esters, FAME) were used to monitor changes in group-specific biomarker compounds in the surface layers of the mat community. Sections ca. $25 \mathrm{~cm}^{2}$ and $1 \mathrm{~cm}$ in depth were removed from the greenhouse mats on $9 / 15 / 00$ and immediately dissected. Samples for fatty acid analysis were taken from freshly collected mats at the field site in November of 1998 and June, 2001 for comparison. The flocculent orange material on the surface of the mat was removed by scrapping the surface with a spatula. An exposed leathery layer of the mat, containing extremely high densities of the filamentous cyanobacterium Microcoleus chthonoplastes (hereafter called the Microcoleus layer), approximately $1-1.5 \mathrm{~mm}$ thick, was then separated using a razor blade from the darker colored gelatinous material that composes the under mat. The three samples were frozen and freeze-dried. Field collected mats were dissected shortly after collection (November, 1998 and June, 2001) in Guerrero Negro, frozen and returned to Ames. The dried mat layers were ground using a glass mortar and pestle. Total lipid extracts were prepared by a Bligh and Dyer (B\&D) single-phase modification (Jahnke et al., 1992). Multiple extractions of the cell material recovered by centrifugation were done until no further pigment coloration was apparent (normally $4 \mathrm{X}$ to $5 \mathrm{X}$ ). A polar fraction (phospholipids and some glycolipids) 
was prepared by precipitation in cold acetone. The remaining acetone soluble lipids were separated by thin layer chromatography using a methylene chloride solvent system (Jahnke et al., 1992). The remaining glycolipids in the origin zone $(0-1 \mathrm{~cm})$ and the sterols (ca. $2.5-3.5 \mathrm{~cm}$ ) were recovered from the silica gel by B\&D extraction. The polar lipid fractions were pooled and fatty acid methyl esters (FAME) prepared by a mild alkaline methanolysis procedure (Jahnke et al., 2001). GC-MS analyses of FAME or sterols as TMS (trimethylsilyl) esters were preformed using an HP 5890 gas chromatograph equipped with a J\&W DB- $5 \mathrm{~ms}$ ( $30 \mathrm{~m}$ by $0.25 \mathrm{~mm}, 0.25 \mu \mathrm{m}$ film) capillary column and an HP 5971 mass-selective detector. Identification of individual compounds was by a combination of standard compounds, published spectra and relative retention times. FAME and TMS esters were quantified using an Agilent 6890 gas chromatograph equipped with an FID and HP-5 (30 $\mathrm{m}$ by $0.32 \mathrm{~mm}, 0.25 \mu \mathrm{m}$ film) capillary column. Methyltricosanoate (FAME) or tetracosanol (sterol) were used as internal standards. Chromatographs were programmed to operate for FAME at $60^{\circ}$ to $120^{\circ} \mathrm{C}$ at $10^{\circ} \mathrm{C} / \mathrm{min}$, then at $2^{\circ} \mathrm{C} / \mathrm{min}$ from $120^{\circ}$ to $280^{\circ} \mathrm{C}$, and for sterol-TMS at $60^{\circ}$ to $200^{\circ} \mathrm{C}$ at $10^{\circ} \mathrm{C} / \mathrm{min}$, then at $4^{\circ} \mathrm{C} / \mathrm{min}$ from $200^{\circ}$ to $300^{\circ} \mathrm{C}$, holding for $10 \mathrm{~min}$. Total organic carbon (TOC) and stable isotope composition $\left(\delta^{13} \mathrm{C}\right.$ and $\left.\delta^{15} \mathrm{~N}\right)$ for biomass was determined using a Carlo Erba CHN EA1 108 elemental analyzer interfaced to a Finnigan Delta Plus XL isotope ratio mass spectrometer (Jahnke et al., 2001).

\section{Fluxes of Oxygen Estimated by Microsensor Measurements}

Net flux across the mat surface was calculated according to Fick's first law of diffusion (Berner, 1980) as ( $\partial \mathrm{C} / \partial \mathrm{X}) \mathrm{DP}$, where $\partial \mathrm{C} / \partial \mathrm{X}$ is the slope of the change in oxygen concentration with depth across the mat surface in $\mu \mathrm{M} / \mu \mathrm{m}, \mathrm{D}$ is the diffusion coefficient $\left(\mathrm{cm}^{-2} \mathrm{~s}^{-1}\right)$ and $\mathrm{P}$ is mat porosity. DP within the mat was estimated as follows. For each salinity treatment, a high-resolution ( $50 \mu \mathrm{m}$ step) vertical profile through both the DBL and the mat was made. D in the DBL was determined based on salinity and temperature of the water column at the time of the profile. Since $P$ in water is 1 by definition, DP in the DBL is known. DP in the mat was then estimated as $(\partial \mathrm{C} / \partial \mathrm{X}) \mathrm{DP}$ (in $\mathrm{DBL}) /(\partial \mathrm{C} / \partial \mathrm{X})$ (in mat). Mat DP estimated in this way was similar to published values, approximately $10^{-6}$.

Fluxes of Oxygen, Dissolved Inorganic Carbon, Methane, and Hydrogen Fluxes of oxygen $\left(\mathrm{O}_{2}\right)$ and dissolved inorganic carbon (DIC) between the mats and the overlying water were measured using glass benthic flux chambers that allowed unimpeded illumination of the surface, with no appreciable $\left(<1^{\circ} \mathrm{C}\right)$ heating of the chamber. The chamber design and operation follows that of Canfield and Des Marais (1993). Briefly, each glass chamber (covering an area of mat ca. 0.019 or $0.012 \mathrm{~m}^{2}$ ) was fitted with a central stirring paddle and two sampling ports with septa. The glass paddle rotated at a constant rate of 4.5 revolutions per minute. Chamber incubations were 
conducted for full 24-hour daily cycles, taking samples by syringe every six hours. When deployed at sunrise, each chamber was injected with ca. $100 \mathrm{ml}$ pure nitrogen $\left(\mathrm{N}_{2}\right)$ gas to create a headspace to sample at noon and before sunset for acquisition of gas samples $\left(\mathrm{O}_{2}, \mathrm{CH}_{4}, \mathrm{H}_{2}\right.$, etc. $)$. At sunset, each chamber was redeployed and injected with $70 \mathrm{ml} \mathrm{N}$ and $30 \mathrm{ml} \mathrm{O}_{2}$ to accommodate $\mathrm{O}_{2}$ demand during the night. Samples were taken at midnight and before sunrise. Dissolved and headspace $\mathrm{O}_{2}$ were measured using a Clark style electrode with an internal reference mounted inside a 21 gauge syringe needle (model 768, Diamond General Development Corporation, Ann Arbor, Michigan, USA) and a gas chromatograph, respectively. The gas chromatograph (Shimadzu GC-14A) was fitted with a thermal conductivity detector and a CTRI column (Alltech Associates, Deerfield, IL, USA) held at $25^{\circ} \mathrm{C}$. Helium, at flow rate of $30 \mathrm{ml} / \mathrm{min}$, was the carrier gas. DIC samples ( $5 \mathrm{ml}$ ) were filtered and analyzed in triplicate using a "flow injection analyzer" (Hall and Aller, 1992), where a sample was injected into an acidified aqueous solution that subsequently flows past a gas-permeable membrane. Carbon dioxide from the acidified DIC sample traverses this membrane and enters an alkaline solution that subsequently flows through a conductivity detector.

\section{Hydrogen Partial Pressures}

While actively photosynthesizing, mats generate small (approx. $1 \mu \mathrm{L}$ ) bubbles that are retained at the mat surface with residence times of tens of minutes. These bubbles were collected by means of a $3-\mathrm{mL}$ plastic syringe with a plastic pipette tip lodged in the luer fitting (flaring outward, to form a collecting funnel). When filled with water and submerged, this apparatus allows individual bubbles to be picked from the mat surface, without atmospheric contamination, and pooled to a volume of $10-25 \mu \mathrm{L}$. The pooled bubble gas is immediately subsampled with a gas-tight volumetric syringe and quantified by GC with HgO-reduction detection (Trace Analytical RGA-3, Sparks, MD, USA). The time from sample collection to analysis was generally $<30$ s. Partial pressures in bubble samples were determined by comparison with standards prepared by serial dilution of pure $\mathrm{H}_{2}$ into $\mathrm{N}_{2}$ (Hoehler et al., 1998). Precision and accuracy are typically about $\pm 5 \%$ for sample volumes in the range of 10-25 $\mu \mathrm{L}$.

\section{Results}

The Greenhouse Facility as a Simulation of the Natural Environment

Microbial mats kept in the greenhouse facility retained an overall appearance remarkably similar to that of freshly collected mats. In particular, no evidence of the mat "greening", in which motile cyanobacteria migrate to the surface of the mat (Bebout and Garcia-

Pichel, 1995), was apparent. During the first few weeks of greenhouse incubation, there was a notable increase in the abundance of loosely attached microbial "floc" at the surface of the mats, as well as the development of small dark green spots containing large 
numbers of cyanobacterial filaments in some mats. However, after the first two months, the loose floc disappeared, and the mat surface was smooth and homogeneous in appearance once again. Microscopic observations revealed no major changes in community composition. More specifically, the major populations of cyanobacteria did not seem to change, and Microcoleus chthonoplastes remained the dominant phototroph, in terms of biovolume.

Molecular analyses based on $16 \mathrm{~S}$ rRNA genes through DGGE fingerprinting were consistent with this absence of significant shifts in the community. The banding pattern of DNA extracted from the greenhouse mats was essentially identical to that of freshly collected mats (Figure 2). Two major bands were present in all of the mat samples (Band $b$ and Band $c$ ). In the greenhouse treatments (Figure 2A), Band $c$ represented $84 \%$ of the observed cyanobacterial diversity, gauged as the percent of total PCR amplificate, while Band $b$ represented $10 \%$. These results are consistent with the structure of field samples (Figure $2 \mathrm{~B}$ ) where Band $c$ represented $79 \%$ of the observed diversity, with Band $b$ accounting for $18 \%$. Two other minor bands were found, but not in all treatments. Band $a$ was present in three of the six greenhouse samples and in the field samples, accounting for $3 \%$ and $2 \%$ of the observed diversity, respectively. Band $d$ was found in all six greenhouse samples at much lower levels $(0.8 \%)$, and accounted for $1.2 \%$ of the observed diversity in the field samples. BLAST similarity searches for the sequenced bands (c.a. $380 \mathrm{bp}$ in length) were performed. Band $b$ had no close matches to any cultured cyanobacterium (only $89 \%$ similar to Oscillatoria amphigranulata strain 23-2, a typical distance between bacterial genera), but did match an unidentified, uncultured cyanobacterium from a microbial mat in Solar Lake, Sinai Peninsula, Egypt (Abed and Garcia-Pichel, 2001) with 94\% similarity. The BLAST results for the remaining two bands both yielded very high similarity $(99 \%)$ to known cultured cyanobacteria. Band $c$ matched the Microcoleus chthonoplastes cluster (Garcia-Pichel et al., 1996) and Band $d$ matched Euhalothece sp. Strain MPI 95AH13 (Garcia-Pichel et al., 1998). Even though we were unable to sequence Band $a$, it most likely represents a diatom plastid (according to previous research and band placement in the denaturant gradient).

The composition of the total esterified fatty acids (TEFA) in natural and greenhouse mats were in most respects similar for both the surface and underlying Microcoleus layer (Table 1). The amount of TEFA recovered for the individual mat samples were reasonably consistent. The majority of this TEFA consisted of $n-16: 0, n-16: 1$ and $n-18: 1$ which together accounted for 60 to $77 \%$ of all FA. Smaller amounts of other straight chain saturated and unsaturated FA (i.e. $n$-14:0, $n-17: 0, n-18: 0, n-17: 1, n-20: 1, n-20: 2$ ) together with various terminally branched FA $(i-14: 0, i-15: 0, a i-15: 0, i-16: 0, i-17: 1, i-$ 17:0, ai-17:0) were present in relatively uniform amounts in all samples. However, subtle differences for TEFA compositions in the surface layer and underlying 
Microcoleus layer of natural mats were noted that were also apparent in the greenhouse mats even after 4 months of experimental treatment (Figure 3 ). The surface layer tended to have higher levels iso-15:1 and iso-16:1 than the Microcoleus layer. In natural mat, these two iso-FA were composed primarily $(90 \%)$ of $\square 4$ positional isomers, previously identified in field collected Nostoc spp. (Potts et al., 1987). All surface layers (in both natural and greenhouse mats) also contained small amounts of anteiso-17:1 which was not detected in the Microcoleus layer. The most striking difference in the surface layer, however, was the presence of relatively large amounts of several polyunsaturated fatty acids (PFA) ( $n$-16:2, $n-18: 2, n-18: 3, n-18: 4, n-20: 4$ and $n$-20:5). The more highly unsaturated $\mathrm{C} 20 \mathrm{FA}$, however, are generally considered diatom biomarkers (Cobelas and Lechado , 1989). The lower Microcoleus layer was also considerably enriched in several fatty acids. Most pronounced were a 10-methyl-16:0 associated with some sulfatereducing bacteria (Dowling et al., 1986; Kohring et al., 1994) and a cy-19:0 which has been used as a biomarker for Thiobacillus spp. (Kerger et al., 1986). In addition, microbial mats maintained in the greenhouse retained the carbon and nitrogen stable isotopic composition of recently collected mats (Table 1)

Measurements of rates of biogeochemical cycling in greenhouse mats were, in general, very similar to rates measured on freshly collected mats. Profiles of oxygen concentration within the greenhouse mats resembled those obtained in situ, both in absolute concentration and distribution with depth (Figure 4). Oxygen fluxes to the water column, calculated from the gradients of these profiles, agreed with oxygen fluxes calculated from in situ profiles over a wide range of light intensities (Figure 5). Similarly, net rates of $\mathrm{O}_{2}$ and DIC production and consumption as determined using flux measurements were similar to those measured in freshly collected mats (Table 2), after allowances are made for the relationship between rates of photosynthesis and seasonallydependent levels of illumination in the greenhouse. Fluxes of methane from the greenhouse mats were reduced slightly $(60 \%)$ from those in freshly collected mats and were essentially equal day and night (Table 2 ). In gas bubbles collected at the mat surface, $\mathrm{H}_{2}$ partial pressures in the low salinity control mats are very similar to those observed in the field (Table 2).

\section{The Greenhouse as a Facility for Experimental Manipulations}

Over the course of the experiment, dramatic differences in the appearance of mats maintained at in situ ("NORMAL" $=90 \%$ ) and elevated ("HIGH" $=120 \%$ ) salinities became apparent. Mats held at high salinities assumed a much more orange color than those incubated at lower salinities. A change in color can be due either to physiological (photopigment) changes in an unchanged community or to population shifts. It is known that increased salinity promotes increasingly oxidative conditions (Garcia-Pichel et al., 1999) and that Microcoleus chthonoplastes can respond to increased salinity by 
increasing the cellular levels of carotenoid (Lopez-Cortes, 1990). Importantly, however, in natural field mats yellow orange mats are typically associated with dominance of cyanobacteria from the Halothece cluster. Microscopic observations revealed a relative increase in the abundance of unicellular cyanobacteria resembling the Halothece type at the surface of the mat.

Initial DGGE analyses supported this observation, with a faint novel band attributable to Halothece appearing in samples collected from all three HIGH salinity greenhouse mat samples (data not shown). However, these initial DGGE samples had been compromised by an accidental thawing. The second set of samples, taken at the same time but not thawed before DNA extraction, did not show this band (Figure 2). Rather, this second set of samples showed similar fingerprints for all greenhouse samples, regardless of the treatment. Upon further investigation, we found that thawing and re-freezing of mat samples before DNA extraction caused the preferential breakage of large-celled $M$. chthonoplastes, and the subsequent degradation of its DNA. Because $M$. chthonoplastes provides the majority of template for PCR amplification, DGGE analyses of samples that had been thawed yields a high-resolution fingerprint of the community members present at low density. It was in such analyses that we could detect community shifts in the form of new bands appearing in all high salinity greenhouses, but in none of the other (data not shown). Sequencing and phylogentic analyses of these novel bands revealed that the new community members belonged to the Halothece Cluster of extremely halotolerant, unicellular cyanobacteria. Thus we may have been witnessing an incipient community shift, but not a full replacement of the principal cyanobacterial populations.

In contrast, lipid biomarker analyses cannot support an increase in the abundance of Halothece spp. in greenhouse mat surface samples. Due to the development of a thicker flocculent surface layer in the higher salinity mats, total organic carbon (TOC) in the surface layer was greater in the HIGH salinity mats. The flocculent surface layer of the HIGH salinity mats yielded $1.9 \mathrm{mg}$ of TOC per $\mathrm{cm}^{2}$ mat surface (vs. $1.6 \mathrm{mg}$ for the NORMAL salinity mats). We have identified two polyunsaturated FA, n-16:2 and n18:2, in a GN isolate, Halothece sp. MPI95P605 (unpublished result). Although diatoms also synthesize 16:2 FA, these organisms tend to have higher amounts of 16:3 and/or 16:4 and rarely 18:2 FA (Cobelas and Lechado, 1989). The absence of more highly unsaturated C16 PFA suggests that 16:2 and 18:2 may serve as a biomarker for the Halothece in the surface layers. Both 16:2 and 18:2 FA were reasonably consistent in both greenhouse treatments. Together these PFA account for $2.00 \mathrm{mg} \mathrm{FA} \mathrm{gm}^{-1} \mathrm{TOC}$ in both greenhouse samples which is a value only slightly higher than either of our natural mat samples (ca. $1.5 \mathrm{mg} \mathrm{gm}^{-1}$ ). However, it should be emphasized that not all cyanobacteria synthesize PFA (Kenyon, 1972; Murata et al., 1992), and these analyses do not necessarily preclude increased abundance of Halothece spp. lacking these PFA. An 
increase in the diatom population in the HIGH salinity mats was more readily documented by increased amounts of two diatom biomarkers, the polyunsaturated FA, 20:4 and 20:5, and the sterol composition. The 20:4 and 20:5 together accounted for 4.38 $\mathrm{mg} \mathrm{gm}^{-1} \mathrm{TOC}$ in the HIGH salinity mats and only $3.16 \mathrm{mg} \mathrm{gm}^{-1} \mathrm{TOC}$ in the NORMAL salinity mats. Both of these values are considerably higher than the natural mat samples (ca. $0.6 \mathrm{mg} \mathrm{gm}^{-1}$ ).

In general it is thought that bacteria respond to higher salinity by synthesizing fatty acids with less saturation and less branching in order to decrease membrane fluidity (Russell, 1993), however, in a halotolerant microalga, Dunaliella salina, growth at higher salinity is associated with an almost 50\% increase in the proportion of 18:3 (Al-Hasan et al., 1987). The increase in this PFA is associated with the mono- and digalactosyldiacylglycerols which predominate in photosynthetic membranes. Sterols, a direct indication of the presence of microeukaryotes in these mat samples, were also more abundant in the HIGH salinity treatment with $1.20 \mathrm{mg} \mathrm{gm}^{-1} \mathrm{vs} .0 .74 \mathrm{mg} \mathrm{gm}^{-1}$ for NORMAL. The two sterols that serve as diatom biomarkers, 24-methylcholesta-5-en$3 \beta o l$ and 24-methylcholesta-5, 22-dien-3ßol, (Volkman, 1986) accounted for ca. $80 \%$ of the total in both greenhouse samples.

There were no differences observed in oxygen profiles in the NORMAL and HIGH salinity mats (Figure 4). Fluxes of $\mathrm{O}_{2}$ were measured at the outset (June, 2000) of the parallel treatment of the mats at two salinities, and five months later (November, 2000). In both cases, no differences in $\mathrm{O}_{2}$ fluxes were apparent between the two salinity treatments, either regarding the rate of export of $\mathrm{O}_{2}$ to the overlying water column during the day, or in the uptake of $\mathrm{O}_{2}$ at night (Rates Data Table). In contrast, rates of methane production from the NORMAL and HIGH salinity mats, which showed no difference for the majority of time that the experiment was running, did appear to be different at the last sampling (8-9 November, 2000) with higher rates recorded in the normal salinity treatment. $\mathrm{H}_{2}$ partial pressure in photosynthetic surface bubbles from the HIGH salinity mats was about half that in the NORMAL salinity mats.

\section{Discussion}

For a period of at least one year, microbial mats that were maintained in the greenhouse facility resembled field collected microbial mats with respect to their overall appearance, cyanobacterial community composition, and rates of biogeochemical cycling. High rates of activity and fast doubling times of microbial populations contribute to the adaptability of these ecosystems, however these attributes also make mat systems especially challenging to preserve in their original, natural states. The phenomenon known as "greening" in which motile cyanobacteria migrate to the surface of the mats, and remain 
there in response to lowered irradiance, is common in mats maintained under artificial illumination (Bebout and Garcia-Pichel, 1995). Microbial mats removed from their natural environment, and maintained in large outdoor ponds became "overgrown" with populations of cyanobacteria that are not necessarily well-represented in situ (Abed and Garcia-Pichel, 2001).

The greenhouse mats described here appear to retain rates of biogeochemical processes very similar to those measured in freshly collected mats. Oxygen microprofiles, measured using microelectrodes, and oxygen and carbon fluxes, measured using flux chambers, are very comparable in greenhouse, and freshly collected natural mats. While it is reassuring to observe this similarity in mat net community metabolism, it is likely that these parameters are among the least sensitive to change as measurements of net carbon and oxygen flux integrate the rates of metabolic activity of most of the microorganisms in the community. Increases in the activity of one group of microorganisms may be compensated for by decreases in the activity of others. More worthy of note, perhaps, is the close similarity between greenhouse and in situ bubble $\mathrm{H}_{2}$ partial pressures. $\mathrm{H}_{2}$ partial pressures in bubbles are extremely sensitive to changes in the environment of photosynthesis in the uppermost mat layer. For example, mats removed from their native pond and placed under conditions of high solar irradiance and low or no water flow frequently exhibit an increase in bubble $\mathrm{H}_{2}$ partial pressures of up to 2 orders of magnitude. The combination of light and flow regimes appears to exert strong and instantaneous control on bubble $\mathrm{H}_{2}$ partial pressures by setting the balance between diffusive DIC supply and light intensity (Lambert and Smith, 1980; Houchins, 1984). The fact that little or no difference is apparent between greenhouse and natural mats suggests that the basic flow and light regimes of the natural environment are recreated to a very high degree in the greenhouse setting.

We believe that the greenhouse approach documented here is among the most successful of the efforts to date to produce an environment appropriate for the long term study of these important microbial communities. When compared to previous efforts to maintain microbial mats, our results indicate that two factors are likely to be more important than others in simulating the field environment, namely water flow and the light regime.

A very thin (ca. $0.5 \mathrm{~mm}$ ) layer of stagnant water, the diffusive boundary layer (DBL), is situated at the interface between any microbial mat community and the water column, even under conditions of high water flow (Jørgensen and Des Marais, 1990). The transport of all solutes between the water column and the mat occurs exclusively by molecular diffusion through the DBL, and so the thickness of this layer sets the rates at which this exchange may take place. Rates of activity, including rates of primary production in microbial mat communities, may be controlled by the rate at which carbon 
dioxide and oxygen diffuse across the DBL (Garcia-Pichel et al., 1999). In the greenhouse facility, water is constantly circulated over the mats, at environmentally realistic flow velocities, using pumps having ceramic impellers. The similarity of greenhouse $\mathrm{O}_{2}$ concentration profiles, $\mathrm{O}_{2}$ fluxes, and DIC fluxes to those measured in situ suggests that the greenhouse flume system closely reproduces the environmental flow field and DBL control on mat-water solute exchange. Microelectrode-based measurements of DBL thickness in situ and in greenhouse flumes confirm this finding (Figure 4).

In photosynthetic microbial mats, all of the energy necessary for growth and maintenance of the community is ultimately derived from the sun's radiant energy. Therefore, these mats are highly sensitive to the intensity and spectral composition of photosynthetically available radiation at the mat surface. Furthermore, many mat microorganisms are motile, utilizing light and/or ultraviolet radiation as a cue to adjust their position in the mats vertically (Castenholz, 1994; Bebout and Garcia-Pichel, 1995). Therefore, oxygen production and consumption by these phototrophic organisms, as well as their sensitivity to ultraviolet radiation, determine the physical structure of the entire mat community. Mats maintained in the greenhouse facility have access to natural solar radiation. The use of artificial illumination to drive photosynthetic activity in microbial mats over longer periods of time is less attractive from a logistical perspective due to the large amounts of heat that is generated. Sources of artificial light rarely reproduce the intensity at the mat surface and even more rarely reproduce the spectral composition of natural sunlight. For both of these reasons, the use of natural sunlight is preferred for the maintenance of these microbial communities. Use of a greenhouse facility for microbial mat maintenance is also the most cost effective way to deliver the required visible and ultraviolet radiation to microbial mat communities, particularly when large areas of mat are required for destructive sampling and/or large numbers of replicate measurements.

Future modification in greenhouse flow and light regimes may further improve our ability to simulate the field environment. The one potentially significant difference in community composition observed between greenhouse and natural mats, namely the apparent increase in the abundance of diatoms in the surface layers suggested by the FAME biomarker data, may, in fact, be explained by differences in the flow regime experienced by mats incubated in the greenhouse relative to in situ conditions. In the greenhouse, the flow of water over the mats, while reproducing natural flow velocities and DBL thickness, occurs 24 hours a day. In the field environment, water flow over the mats is primarily wind-driven and, as such, is variable over the course of the day. Strong winds are characteristic of the afternoon; as rising warm air is replaced by strong onshore breezes. At night, and into the morning, there is very little wind and therefore, very little flow of water over the mats. Recently, we have documented a density stratification of the 
ponds at night. This density stratification, in combination with high rates of oxygen consumption by the mat, results in a layer of anoxic bottom water several centimeters thick that persists until late in the morning (Scott R. Miller, unpublished data). Hydrogen sulfide, produced in the mat by sulfate reduction, reaches levels in excess of $185 \mu \mathrm{M}$ in this layer (Bo Thamdrup, unpublished data). Additionally, we recently documented that temperatures at the mat surface are often several degrees higher than those in the middle of the water column, and those which we have been simulating in the greenhouse. This is presumably due to greater heat retention by the sediments underlying the microbial mats in their natural environment. Constant flow over the greenhouse mats would tend to diffuse heat from the surface layers of the mat, resulting in temperatures lower than those recorded in situ.

The lack of exposure to anoxic, sulfidic water at night, as well as greenhouse water temperatures lower than those experienced by the mats in situ, would tend to increase the abundance of diatoms relative to unicellular cyanobacteria in the surface layers of the greenhouse mats. The photosynthetic performance of the diatoms may be inhibited in situ as a result of the sulfide sensitivity of oxygenic photosynthesis (Oren et al., 1979). Unicellular cyanobacteria from microbial mats are well known to grow optimally at relatively high temperatures (Dor and Paz, 1989; Garcia-Pichel et al., 1998). Future work in the greenhouse will investigate the extent to which periodic and/or nighttime periods of low flow, as well as periodic higher temperature excursions, might reduce the propensity of the diatoms to dominate the surface layers of the mat.

The microbial mats in our greenhouse simulation facility represent a resource from which we would like to obtain diverse observations and as much data necessary to address key questions in ecology. In order to increase the accessibility of the greenhouse to members of the research group, the facility is being transformed into a "collaboratory". The collaboratory will enable a geographically distributed group of scientists to plan experiments, operate scientific equipment, take experimental measurements, share results, and collaborate in real time with remote colleagues. Within the collaboratory, intelligent software agents will assist in the experimentation process, controlling the hardware, troubleshooting, recording results, and reporting back to collaborating experimenters. The XYZ positioning table over the mats is capable of automatically positioning sophisticated instruments at any location over and within the mats. The instrument package currently includes microelectrodes, a light sensor, chlorophyll fluorometer, a surface detection device, and a fiber optic spectrometer. The positioning system, and the instrumentation package is viewable over the internet (http://greencam.arc.nasa.gov) via a webcam connected to a computer located in the greenhouse. The advanced automation capabilities in the greenhouse will enable longerterm experimentation, 24 hours a day, without the costs associated with extensive human 
supervision. The remote collaboration capabilities will extend this experimental resource to colleagues not physically present in the greenhouse.

In summary, in addition to reproducing rates of in situ biogeochemical processes rather closely, greenhouse microbial mats were responsive to manipulations of environmental conditions. Increasing the salinity of water in the greenhouse facility reproduced some of the community composition changes observed in natural mats growing at higher salinities. The differences that were observed in the salinity responses of natural and greenhouse mats may be consistent with expected differences between field and greenhouse environmental conditions, e.g., differences in temperature and nighttime oxygen and hydrogen sulfide concentrations. Therefore, we are optimistic that this facility may now be used not only to maintain mats with natural levels of activity and species composition, but also to explore environmental conditions that are not presently found in the natural environment, e.g., low sulfate and low oxygen environments.

\section{References}

Abed, A. M. M. and Garcia-Pichel, F. (2001) Long-term compositional changes after transplant in a microbial mat cyanobacterial community revealed using a polyphasic approach. Environmental Microbiology, 3: 53-62.

Al-Hasan, R. H., Ghannoum, M. A., Sallal, A.-K., Abu-Elteen, K. H. and Radwan, S. S. (1987) Correlative changes of growth, pigmentation and lipid composition of Dunaliella salina in response to halostress. Journal of General Microbiology, 133: 2607-2616.

Amann, R. I., Ludwig, W. and Schleifer, K. H. (1995) Phylogenetic identification and in situ detection of individual microbial cells without cultivation. Microbiological Reviews, 59: 143-169.

Bebout, B. M. and Garcia-Pichel, F. (1995) UVB-induced vertical migrations of cyanobacteria in a microbial mat. Applied and Environmental Microbiology, 61: 4215-4222.

Berner, R. A. (1980) Early Diagenesis: A Theoretical Approach. Princeton, Princeton University Press.

Beukes, N. J. and Lowe, D. R. (1989) Environmental control on diverse stromatolite morphologies in the 3000 Myr Pongola Supergroup, South Africa. Sedimentology, 36: 383-397.

Boon, J. J. (1984) Tracing the origin of chemical fossils in microbial mats:

Biogeochemical investigations of solar lake cyanobacterial mats using analytical pyrolysis methods. In: Microbial Mats: Stromatolites. Y. Cohen, R. W.

Castenholz and H. O. Halvorson, Alan R. Liss, Inc., New York: 313-342. 
Canfield, D. E. and Des Marais, D. J. (1991) Aerobic sulfate reduction in microbial mats. Science, 251: 1471-1473.

Canfield, D. E. and Des Marais, D. J. (1993) Biogeochemical cycles of carbon, sulfur and free oxygen in a microbial mat. Geochimica et Comochimica Acta, 57: 3971 3984.

Canfield, D. E. and Teske, A. (1996) Late Proterozoic rise in atmospheric oxygen from phylogenetic and stable isotope studies. Nature, 382: 127-132.

L. I. Caroff and D. J. Des Marais, eds. (2000) Pale Blue Dot 2 Workshop: Habitable and Inhabited Worlds Beyond Our Own Solar System. NASA Conference Publication 2000-209595.

Castenholz, R. W. (1994) Microbial mat research: The recent past and new perspectives. In: Microbial Mats: Structure, Development and Environmental Significance. L. J. Stal and P. Caumette. Berlin, Springer-Verlag. G 35: 265-271.

Cobelas, M. A. and Lechado, J. Z. (1989) Lipids in microalgae. A review. I. Biochemistry. Grasas y Aceites, 40: 118-145.

Des Marais, D. J. (1995) The biogeochemistry of hypersaline microbial mats. Advances in Microbial Ecology, 14: 251-274.

Des Marais, D. J. and Canfield, D. E. (1994) The carbon isotope biogeochemistry of microbial mats. In: Microbial Mats: Structure, Development and Environmental Significance. L. J. Stal and P. Caumette. Berlin, Springer-Verlag. G 35: 289-298.

Des Marais, D. J., Harwqitt, M., Jucks, K., Kasting, J. J., Lunine, J. L., Lin, D., Seager, S., Schneider, J., Traub, W. and Woolf, N. (2001) Biosignatures and Planetary Properties to be Investigated by the TPF Mission. Pasadena, CA, Jet Propulsion Laboratory.

Dor, I. and Paz, N. (1989) Temporal and spatial distribution of mat microalgae in the experimental solar ponds, Dea Sea area, Israel. In: Microbial Mats: The Physiological Ecology of Benthic Microbial Communities. Y. Cohen and E. Rosenberg. Washington, D.C., American Society for Microbiology: 114-122.

Dowling, N. J. E., Widdel, F. and White, D. C. (1986) Phospholipid Ester-linked fatty acid biomarkers of acetate-oxidizing sulphate-reducers and other sulphideforming bacteria. Journal of General Microbiology, 132: 1815-1825.

Garcia-Pichel, F., Kühl, M., Nübel, U. and Muyzer, G. (1999) Salinity-dependent limitation of photosynthesis and oxygen exchange in microbial mats. Journal of Phycology, 35: 227-238.

Garcia-Pichel, F., Nübel, U. and Muyzer, G. (1998) The phylogeny of unicellular, extremely halotolerant cyanobacteria. Archives of Microbiology, 169: 469-482.

Garcia-Pichel, F., Prufert-Bebout, L. and Muyzer, G. (1996) Phenotypic and phylogenetic analyses show Microcoleus chthonoplastes to be a cosmopolitan cyanobacterium. Applied and Environmental Microbiology, 62: 3284-3291. 
Garret, P. (1970) Phanerozoic stromatolites: noncompetitive ecological restriction by grazing and burrowing animals. Science, 169: 171-173.

Hall, P. O. J, and Aller, R. C. (1992) Rapid, small-volume, flow injection analysis for $\Sigma \mathrm{CO}_{2}$ and $\mathrm{NH}_{4}{ }^{+}$in marine and freshwaters. Limnology and Oceanography, 37: 1113-1119.

Hoehler, T. M., Alperin, M. J., Albert, D. B. and Martens, C. S. (1998) Thermodynamic control on $\mathrm{H}_{2}$ concentrations in an anoxic marine sediment. Geochimica et Cosmochimica Acta, 62: 1745-1756.

Hoehler, T. M., Bebout, B. M. and Des Marais, D. J. (2001) The role of microbial mats in the production of reduced gases on the early Earth. Nature, 412: 324-327.

Holland, H. D. (1984) The Chemical Evolution of the Atmosphere and Oceans. Princeton, Princeton University Press.

Houchins, J. P. (1984) The physiology and biochemistry of hydrogen metabolism in cyanobacteria. Biochimica et Biophysica Acta, 768: 227-255.

Jahnke, L. L., Eder, W., Huber, R., Hope, J. M., Hinrichs, K.-U., Hayes, J. M., Des Marais, D. J., Cady, S. L. and Summons, R. E. (2001) Signature lipids and stable carbon isotope analyses of Octopus Spring hyperthermophilic communities compared with those of Aquificales representatives. Applied and Environmental Microbiology, 67: 5179-5189.

Jahnke, L. L., Stan-Lotter, H., Kato, K. and Hochstein, L. I. (1992) Presence of methyl sterol and bacteriohopanepolyol in an outer-membrane preparation from Methylococcus capsulatus (Bath). J Gen Microbiol., 138: 1759-1766.

Jørgensen, B. B. and Des Marais, D. J. (1990) The diffusive boundary layer of sediments: Oxygen microgradients over a microbial mat. Limnology and Oceanography, 35: 1343-1355.

Jørgensen, B. B., Revsbech, N. P., Blackburn, T. H. and Cohen, Y. (1979) Diurnal cycle of oxygen and sulfide microgradients and microbial photosynthesis in a cyanobacterial mat sediment. Applied and Environmental Microbiology, 38: 4658.

Kenyon, C. N. (1972) Fatty acid composition of unicellular strains of blue-green algae. Journal of Bacteriology, 109: 827-834.

Kerger, B. D., Nichols, P. D., Antworth, C. P., Sand, W., Bock, E., Cox, J. C., Langworthy, T. A. and White, D. C. (1986) Signature fatty acids in the polar lipids of acid-producing Thiobacillus spp.: methoxy, cyclopropyl, alpha-hydroxycyclopropyl and branched and normal monoenoic fatty acids. FEMS Microbiology Ecology, 38: 67-77.

Kohring, L. L., Ringelberg, D. B., Devereux, R., Stahl, D. A., Mittelman, M. W. and While, D. C. (1994) Comparison of phylogenetic relationships based on phospholipid fatty acid profiles and ribosomal RNA sequence similarities among 
dissimilatory sulfate-reducing bacteria. FEMS Microbiology Letters, 119: 303308.

Lambert, G. R. and Smith, G. D. (1980) The hydrogen metabolism of cyanobacteria (blue-green algae). Biology Review of the Cambridge Philosophical Society, 56: 589-660.

Lopez-Cortes, A. (1990) Microbial mats in tidal channels at San Carlos, Baja California, Sur, Mexico. Geomicrobiology Journal, 8: 69-85.

Murata, N., Wada, H. and Gombos, Z. (1992) Modes of fatty-acid desaturation in cyanobacteria. Plant Cell Physiology, 33: 933-941.

Nübel, U., Bateson, M. M., Madigan, M. T., Kühl, M. and Ward, D. M. (2001) Diversity and distribution in hypersaline mats of Bacteria related to Chloroflexus spp. Applied and Environmental Microbiology, 67: 4365-4371.

Nübel, U., Garcia-Pichel, F. and Muyzer, G. (1997) PCR primers to amplify 16S rRNA genes from cyanobacteria. Applied and Environmental Microbiology, 63: 33273332.

Oren, A., Padan, E. and Malkin, S. (1979) Sulfide inhibition of photosystem II in cyanobacteria (blue green algae) and tobacco chloroplasts. Biochimica et Biophysica Acta, 546: 270-279.

Potts, M., Olie, J. J., Nickels, J. S., Parsons, J. and White, D. C. (1987) Variation in phospholipid ester-linked fatty acids and carotenoids of dessicated Nostoc commune (Cyanobacteria) from different geographoc locations. Applied and Environmental Microbiology, 53: 4-9.

Reeburgh, W. S. (1980) Anaerobic methane oxidation: rate depth distributions in Skan Bay sediments. Earth Planet. Sci. Lett., 47: 345-352.

Reid, R. P., Visscher, P. T., Decho, A. W., Stolz, J. F., Bebout, B. M., Dupraz, C., Macintyre, I. G., Pinckney, J., Paerl, H. W., Prufert-Bebout, L., Steppe, T. F. and DesMarais, D. J. (2000) The role of microbes in accretion, lamination and lithification in modern marine stromatolites. Nature, 406: 989-992.

Revsbech, N. P. and Jørgensen, B. B. (1986) Microelectrodes: Their use in microbial ecology. Advances in Microbial Ecology, 9: 293-352.

Revsbech, N. P., Jørgensen, B. B., Blackburn, T. H. and Cohen, Y. (1983) Microelectrode studies of the photosynthesis and $\mathrm{O}_{2}, \mathrm{H}_{2} \mathrm{~S}$, and $\mathrm{pH}$ profiles of a microbial mat. Limnology and Oceanography, 28: 1062-1074.

Russell, N. J. (1993) Lipids of halophilic and halotolerant microorganisms. In: The Biology of Halophilic Bacteria. R. H. Vreeland and L. I. Hochstein. Boca Raton, CRC Press: 165-210.

Schidlowski, M. (1988) A 3,800-year-old isotopic record of life from carbon in sedimentary rocks. Nature, 333: 313-318.

Visscher, P. T. and Kiene, R. P. (1994) Production and consumption of volatile organosulfur compounds in microbial mats. In: Microbial Mats: Structure, 
Development, and Environmental Significance. L. J. Stal and P. Caumette. Berlin, Springer Velag: 279-284.

Visscher, P. T. and Van Gemerden, H. (1991) Production and consumption of dimethylsulfonioproprionate in marine microbial mats. Applied and Environmental Microbiology, 57: 3237-3242.

Volkman, J. K. (1986) A review of sterol markers for marine and terrigenous organic matter. Organic Geochemistry, 9: 83-99.

Walter, M. R. (1976) Stromatolites. Amsterdam, Elsevier Scientific Publishing Company. Ward, D. M., Brassell, S. C. and Eglinton, G. (1985) Archaebacterial lipids in hot-spring microbial mats. Nature, 318: 656-659.

Ward, D. M., Weller, R. and Bateson, M. M. (1990) 16S rRNA sequences reveal numerous uncultured microorganisms in a natural community. Nature, 345: 6365.

Wilson, M. V. and Botkin, D. B. (1990) Models of simple microcosms: Emergent properties and the effect of complexity on stability. Am. Nat., 135: 414-434.

\section{Acknowledgents}

This study was supported by grants form the NASA Astrobiology Institute, the NASA Exobiology Program and the Ames Director's Discretionary Fund. The greenhouse XYZ table was designed and constructed by Dan Andrews and Brian Koss, Code FE, NASA Ames Research Center, and funded by the NASA Intelligent Systems Program. 


\section{Figure Captions:}

Figure 1: Microbial mats positioned on the table used in the latter half of the experiment. Three mats are incubated in each of the six acrylic flow boxes. The positions of the reservoirs and temperature control equipment can be seen, as well as the instrument package present on the remotely-operable $X Y Z$ table.

Figure 2: DGGE fingerprints of PCR-amplified cyanobacterial 16S rRNA genes of the six flume treatments (A) and field samples (B). Arrows indicate bands used for further analysis of the fingerprints. Bands $b, c$, and $d$ were excised, re-amplified and sequenced. Figure 3: Relative distribution of various fatty acids characteristic of the (A) surface layer and/or (B) the underlying Microcoleus layer for two natural mats collected from pond 4 near 5 in June 2001 (black bars) and December 1998 (white bars), and for similar mats maintained for over 4 months in a flumes at salinities of $90 \%$ (thatched bars) or of $120 \%$ (dotted bars).

Figure 4: Oxygen microelectrode profiles within microbial mat in the daytime $(1000 \mathrm{~h}$, open symbols) and nighttime (2200h, closed symbols). Very little difference can be seen in profiles taken in mats incubated at NORMAL (squares) and HIGH (circles) salinity.

Figure 5: Microelectrodes were used to monitor oxygen fluxes across the Area 4 mat surface-water interface during greenhouse (squares, NORMAL salinity and circles, $\mathrm{HIGH}$ salinity) and in situ (triangles) experiments. Positive fluxes indicate net flux of photosynthetically-generated oxygen out of the mat, while negative fluxes indicate net oxygen consumption. Error bars are standard errors. Mats maintained in the greenhouse retain the general diel pattern observed in situ, including a moming peak in photosynthesis. Note shading events caused by greenhouse window crossbars resulting in temporary light limitation of photosynthesis in small areas of the greenhouse mats, e.g., at 13:30 on Day One and at 10:30 on Day Two. 
5
5
0
5
0
0
0

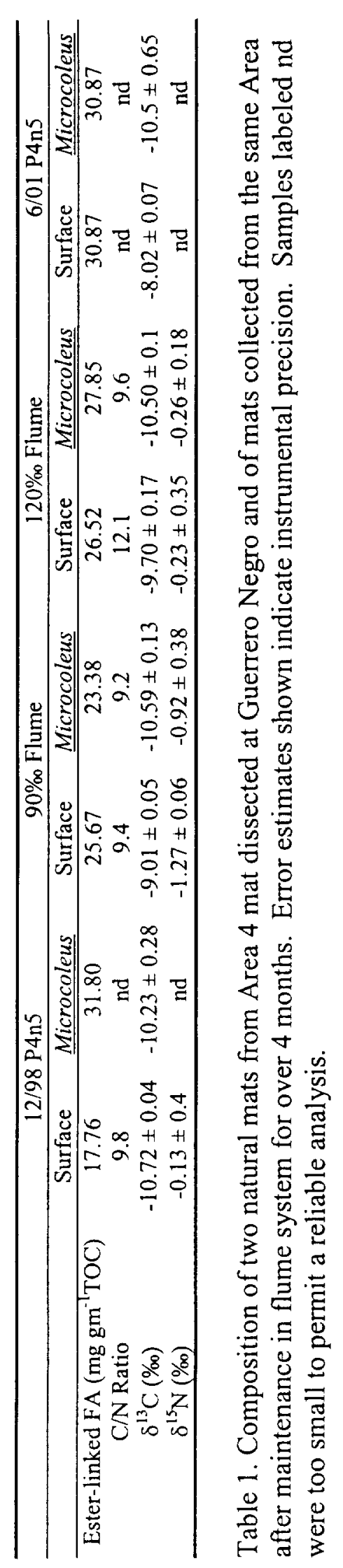




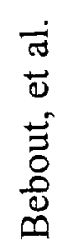

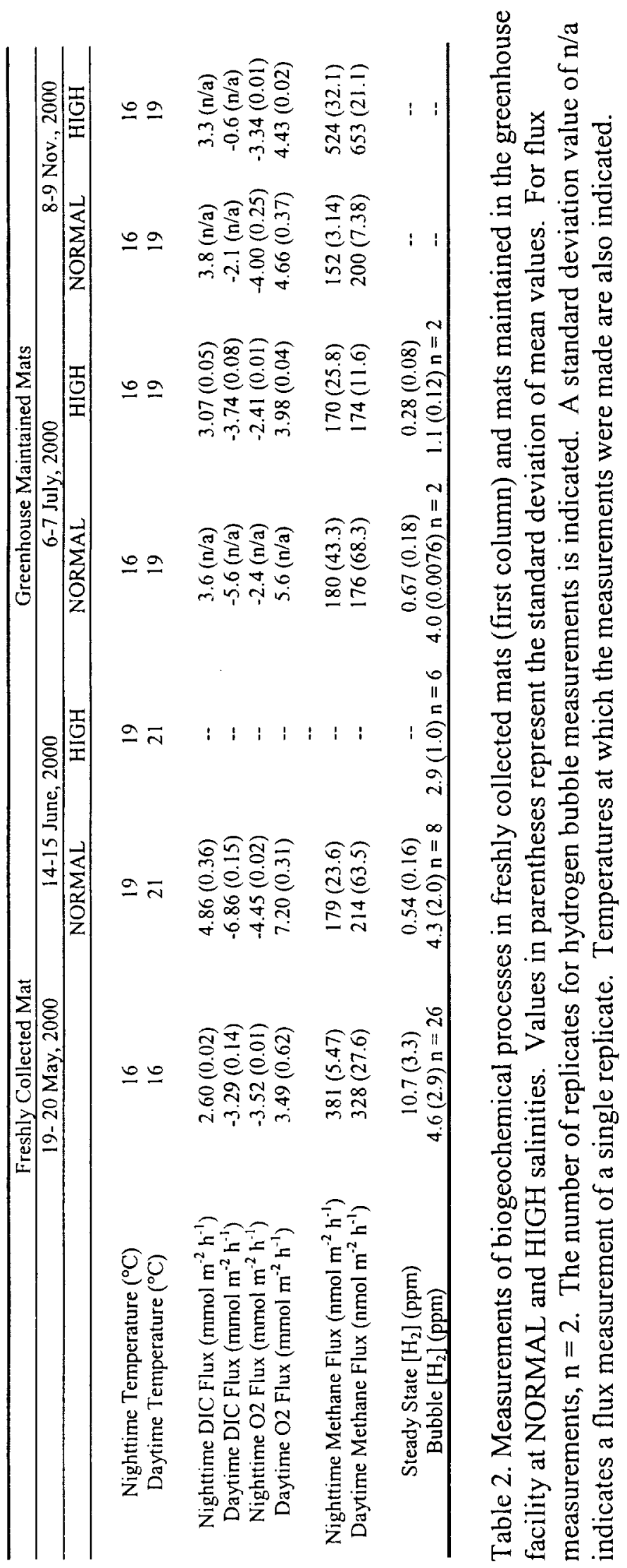




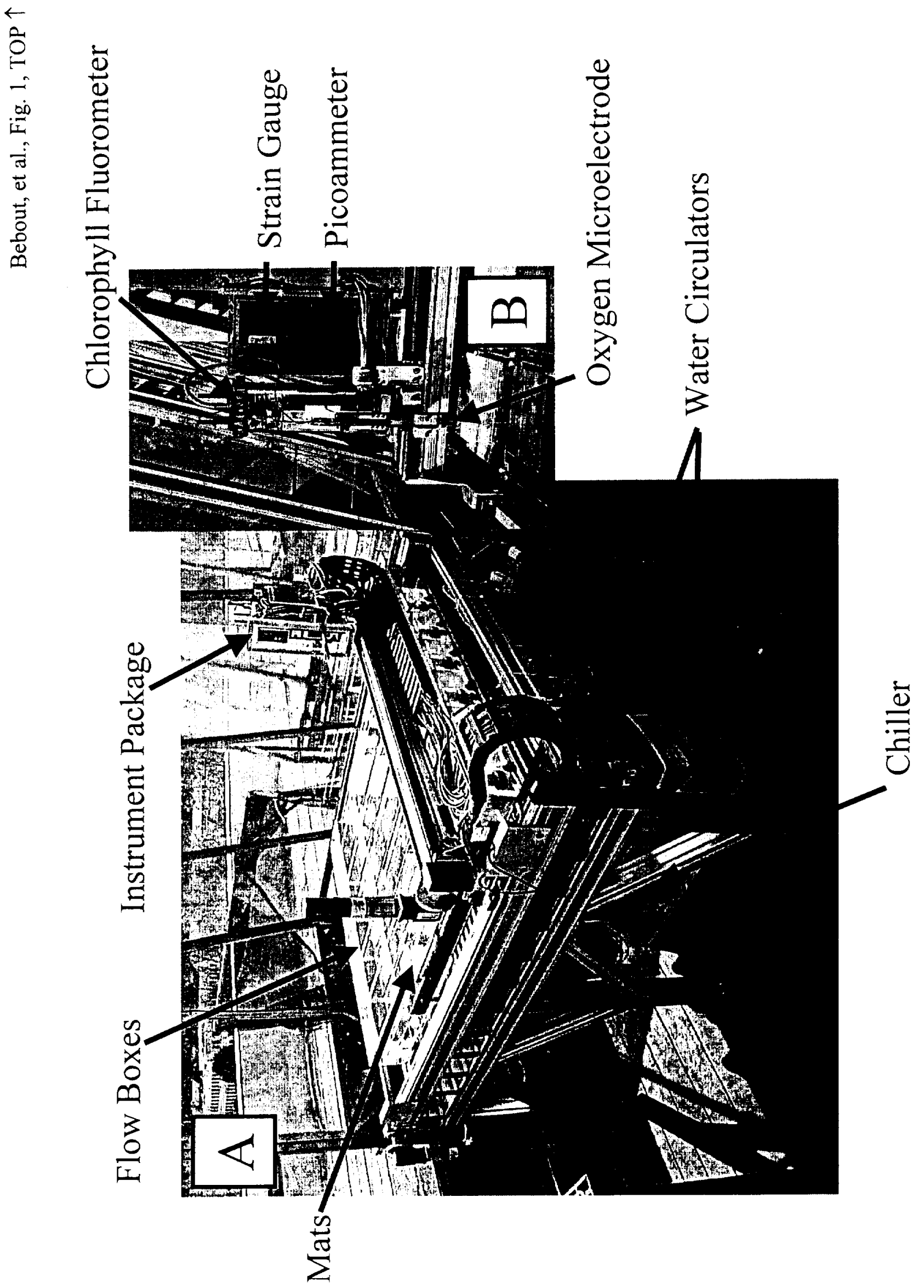




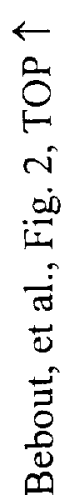
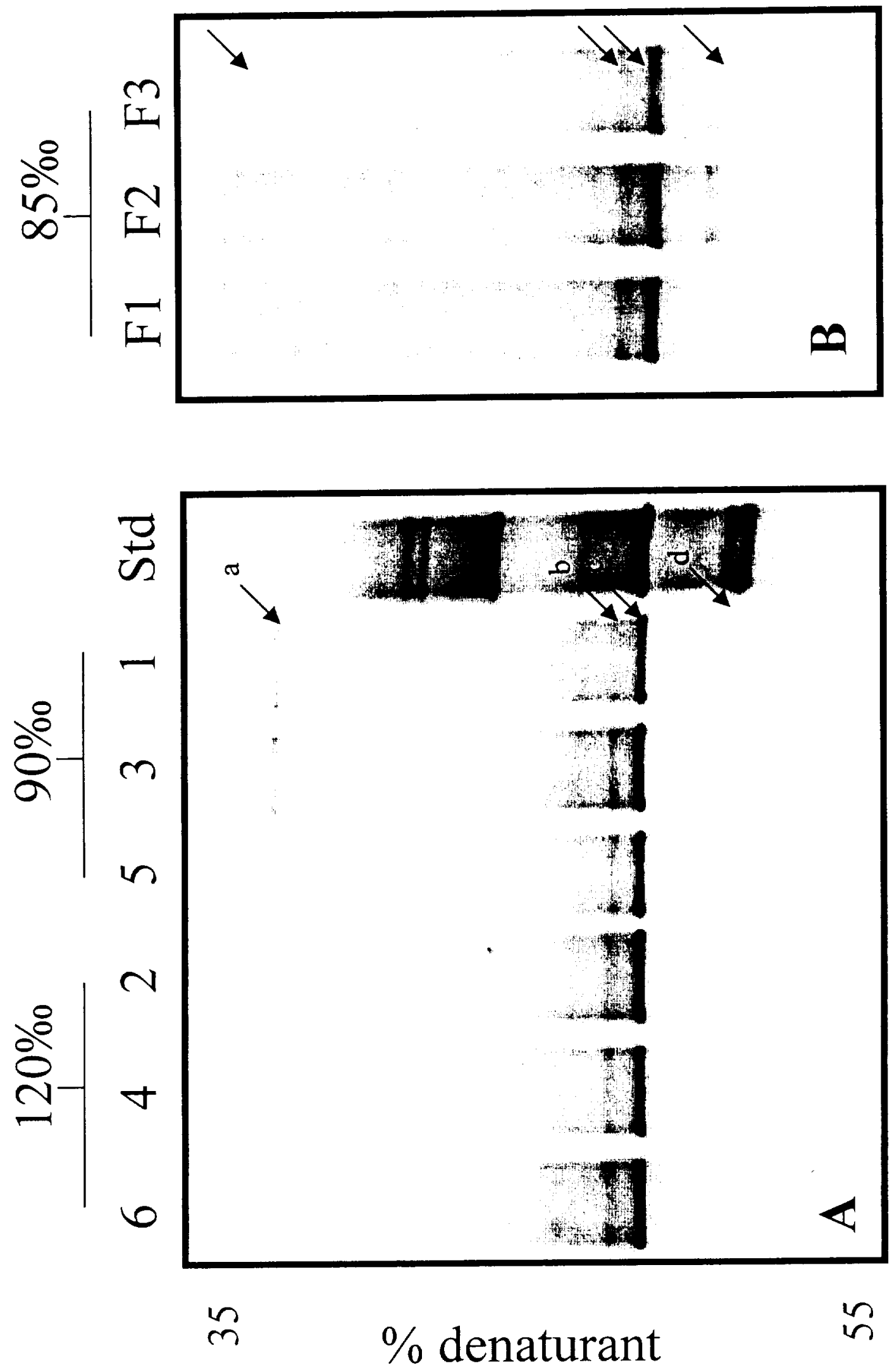

$\underset{\Xi}{\stackrel{\Xi}{\Xi}} \stackrel{\Xi}{\Xi}$ 
Bebout, et al., Fig. 2, TOP $\uparrow$

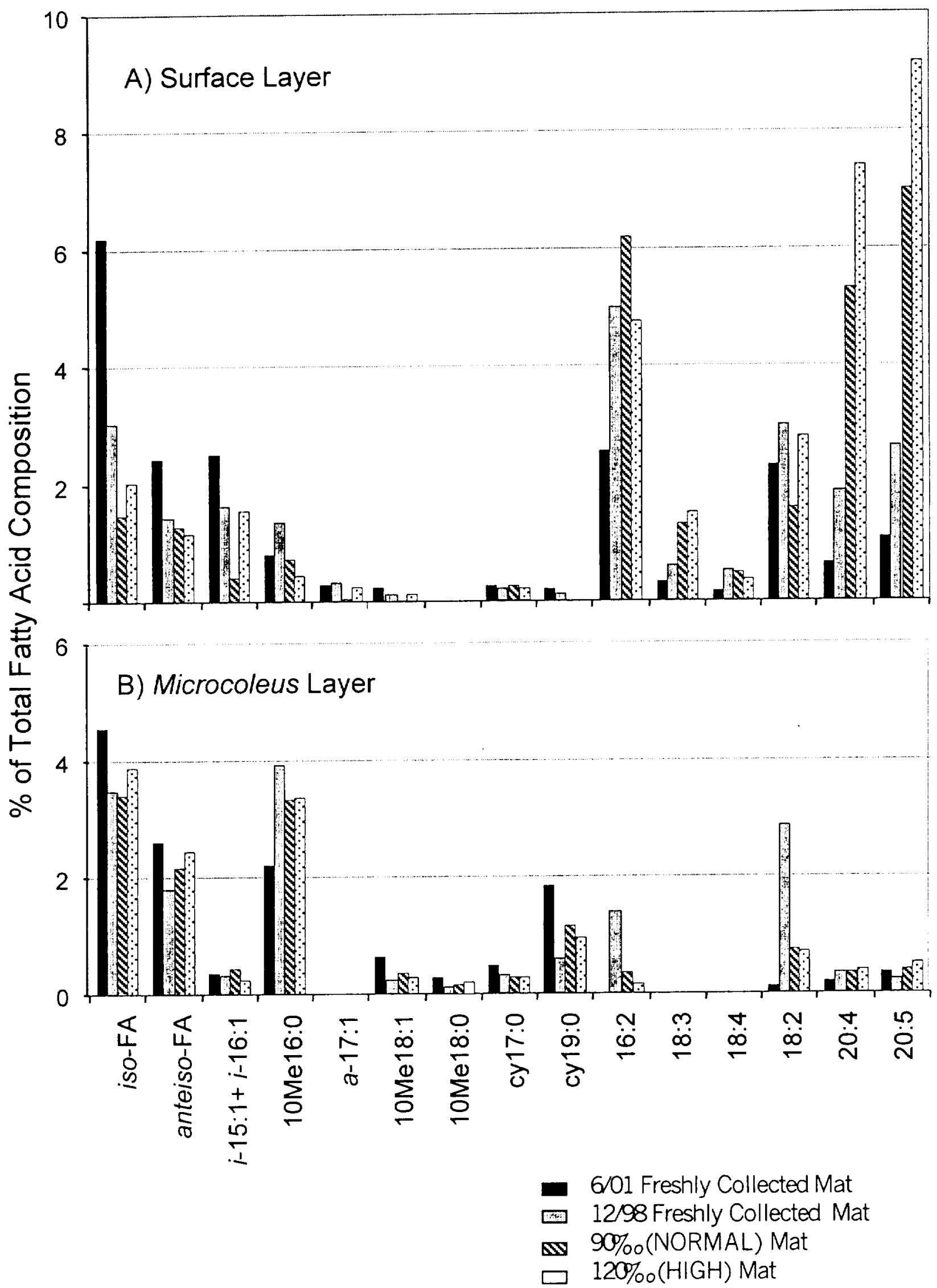




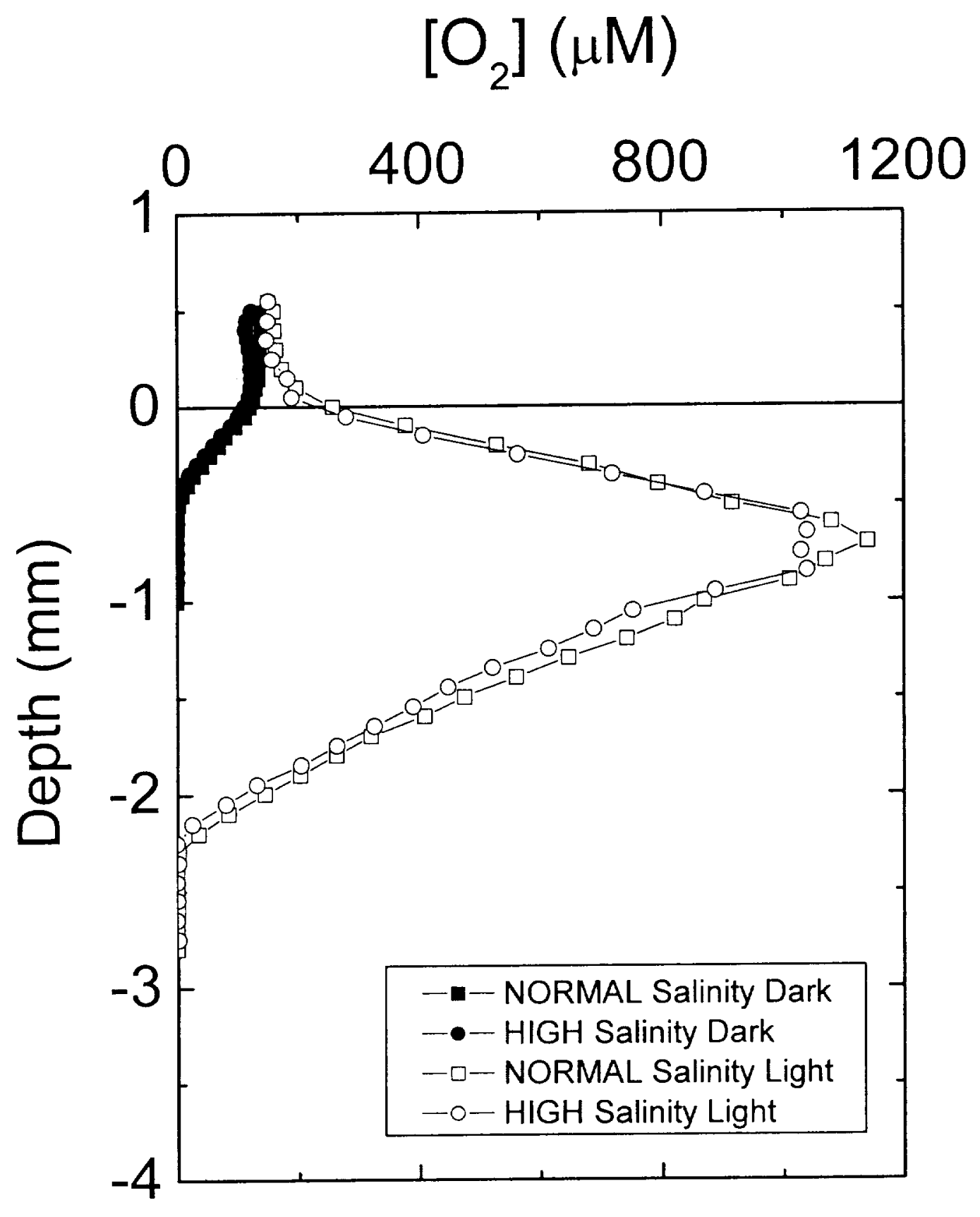




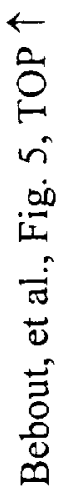

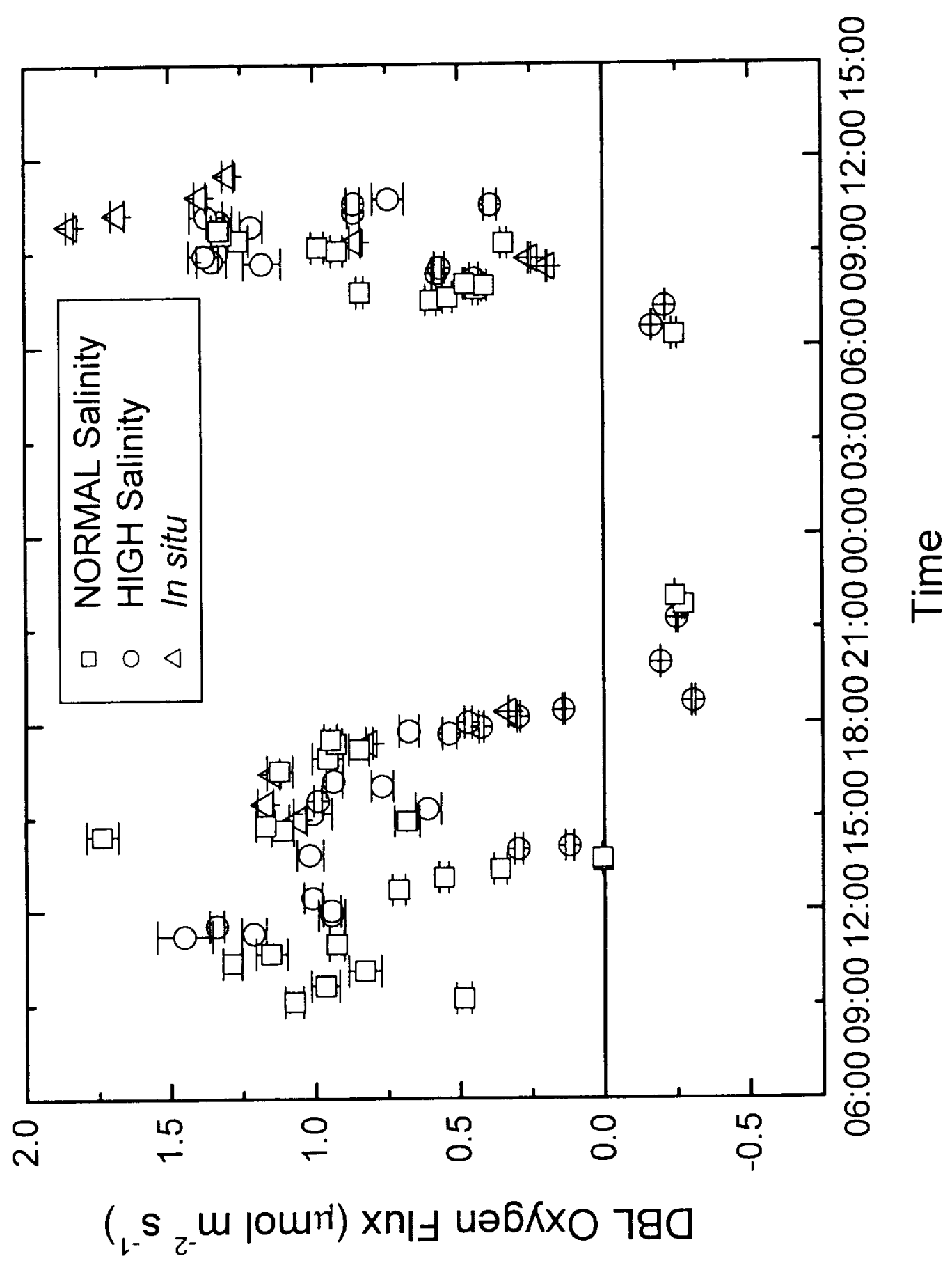

